\title{
Escritura coreográfica de Sandro Borelli frente às novas configurações da dança paulistana
}

Vanessa Macedo ${ }^{1}$

\section{Resumo}

Este artigo traça um breve panorama da influência dos editais, principalmente do Programa de Fomento à Dança, na configuração da dança paulistana. Partindo dessa questão, revela o pensamento do coreógrafo Sandro Borelli, investigando as implicações estéticas e dramatúrgicas que as políticas culturais trazem para sua obra.

Palavras-chave: Dança Paulistana Contemporânea; Política dos Editais; Cia Borelli de Dança

\section{Sandro Borelli's choreographic scripture before the new dance configuration in São Paulo city}

\section{Abstract}

This article provides a brief overview of the influence of edicts, especially the Dance incentive Program, in dance configuration of São Paulo city. On that issue, reveals the choreographer Sandro Borelli's thinking, investigating the aesthetic and dramaturgical implications that Cultural Policies bring to his work.

Keywords: Contemporary Dance of São Paulo City; edicts policy; Cia Borelli Dance

Este estudo é parte da pesquisa de doutorado da autora, e tem como referências: sua inserção, desde 2002, no cenário da dança independente paulistana; sua atuação por 7 anos na Cia Borelli de Dança²; duas entrevistas concedidas pelo coreógrafo e diretor Sandro Borelli. É, partindo desse lugar experenciado pela pesquisadora, que se constrói um olhar para modos de configuração da dança na cidade de São Paulo. Aqui se propõe investigar, frente às políticas culturais, o pensamento do coreógrafo Sandro Borelli, considerando a possibilidade de transformações ou não na sua estrutura interna de trabalho, na forma como propõe seus projetos poéticos e na dramaturgia de sua obra, antes e depois do advento dos editais, principalmente, do Programa de Fomento à Dança.

\footnotetext{
${ }^{1}$ Coreógrafa, diretora e interprete da Cia Fragmento de Dança. Atualmente é doutoranda em artes cênicas pela ECA-USP.

${ }^{2}$ Criada no ano de 1997, a Cia Borelli de Dança é uma das Companhias de maior atuação no Estado de São Paulo. Seu coreógrafo e diretor, Sandro Borelli, é reconhecido por imprimir uma densidade cênica singular em suas criações, inspirado em temas que tratam dos conflitos sócio-políticos do homem contemporâneo.
} 
Instituído no ano de 2005, o Programa Municipal de Fomento à Dança para a cidade de São Paulo, expandiu notadamente a dança paulistana, revelando novas formas de organização e produção artística no município de São Paulo. Hoje referência nacional, o Fomento à Dança nasce, tendo como modelo o Fomento ao Teatro (criado no ano de 2002), de uma demanda dos artistas independentes que reivindicavam políticas culturais para as pesquisas de trabalhos continuados em dança contemporânea. Desde a sua criação foram publicados 13 editais, inscritos 519 e contemplados um total de 175 projetos $^{3}$. Segundo dados do livro "Fomento à Dança - 5 anos", lançado em setembro deste ano, 56 núcleos artísticos ${ }^{4}$ já foram subvencionados pelo programa em questão.

O Fomento à dança não só contribuiu para manter e difundir os artistas e grupos já existentes e com reconhecidas pesquisas na área, como também tornou possível que uma série de jovens artistas que iniciavam suas pesquisas conquistasse seu espaço no cenário da dança. O número de núcleos artísticos cresceu consideravelmente, assim como também cresceu a oferta de espetáculos na cidade. Na última década, junto ao fomento, outros editais contribuíram para a produção da dança paulistana. Nenhum deles, no entanto, atua para isso com tanta eficácia quanto o fomento à Dança, visto que este programa não surge para possibilitar projetos pontuais, e sim projetos de trabalho continuado. As palavras da coordenadora do núcleo de Fomento à Dança, Elaine Calux, confirmam o seu papel diferenciador:

\begin{abstract}
À luz do Fomento, companhias já existentes se estruturaram e novas formações surgiram; a dança conquistou espaço, tanto no sentido das demandas pelo crescimento substancial da oferta e de resultados artísticos, como no aspecto físico, relacionado ao aumento dos equipamentos culturais capazes de receber tais criações e ações. Esse impulso se traduz ainda no processo de profissionalização e ampliação do campo de trabalho de atividades correlatas, numa lista que inclui desde funções ligadas à criação e execução de luz, som e cenografia, comumente presentes em fichas técnicas de trabalhos, à atuação de colaboradores e pesquisadores o pensamento científico e filosófico, passando pelas figuras do produtor, curador, dramaturgo e outros tantos "novos" especialistas. (CALUX, Fomento à Dança - Uma biografia autorizada, In: Fomento à Dança 5 anos, 2012, 124).
\end{abstract}

Como consequência desse panorama, os modos de existir da dança independente, considerando a forma como os artistas se organizam e produzem, ganham uma

\footnotetext{
${ }^{3}$ Dados disponíveis em http://www.prefeitura.sp.gov.br/cidade/secretarias/cultura/fomentos/danca/ e atualizados junto à secretaria municipal de cultura, em mensagem eletrônica recebida < nemacedo@hotmail.com > em 24 de set. de 2012.

${ }^{4}$ Núcleo artístico foi o nome dado pela lei no 14.071 , que instituiu o Programa de Fomento à Dança, ao conjunto de pessoas responsáveis pela fundamentação e execução do projeto. Esse termo, desde então, passou a denominar modos de organização tanto de artistas solos, como de grupos, companhias e coletivos.
} 
nova configuração. Trabalhar por projetos e em vários projetos simultaneamente passa a ser uma realidade, principalmente, para esses jovens artistas que tiveram suas produções desde sempre amparadas, mesmo que de forma não satisfatória, pela política dos editais. O mercado da dança se expande e os responsáveis diretamente pelos projetos artísticos, os chamados proponentes, passam a trabalhar de formas variadas. Alguns tentam manter um elenco fixo, mesmo diante das possíveis lacunas existentes entre um edital e outro; alguns trabalham com profissionais variados, renovando o seu núcleo artístico segundo as necessidades e a natureza do projeto proposto; outros tantos se organizam de forma coletiva ou colaborativa, permitindo que todos sejam responsáveis pela existência e execução da proposta artística, numa estrutura mais horizontalizada. Todas essas formas de organização geram possibilidades de abordagens diversas nos processos criativos desses núcleos, com consequentes produções artísticas e construções dramatúrgicas também diversas. Inicialmente, no entanto, faz-se necessário considerar que a dramaturgia em dança a que se refere esta pesquisa é entendida como a tessitura da obra, a percepção e construção de sentidos que reconhecemos numa criação, mas que pertence a um lugar invisível, conforme indica Ana Pais:

\footnotetext{
Sendo invisível, a dramaturgia só se deixa detectar quando o espetáculo é representado; ela só é perceptível por meio de uma concretização material, visível. Ela é indissociável da obra porque participa de todas as escolhas que a estruturam, mas permanece invisível; pertence à esfera da concepção do espetáculo, uma espécie de fio que nele tece ligações de sentido, criando um discurso. Simultaneamente dramatúrgico e performático, esse discurso caracteriza-se por um movimento que envolve a teia latente de sentidos fabricados e entrelaça todos os materiais estéticos (PAIS, 2010, p. 88).
}

O diretor e coreógrafo Sandro Borelli faz parte da geração dos artistas independentes da dança dos anos 90 . Num período no qual, praticamente, não se dispunha de editais em nenhuma das esferas municipal, estadual ou federal, e os artistas costumavam produzir sem aportes financeiros e encontrar outros meios de sobrevivência. Segundo Borelli, em entrevista concedida à pesquisadora em 23 de setembro de 2012, eram épocas românticas e que foram responsáveis pelo surgimento de uma série de artistas que hoje possuem uma trajetória consolidada.

O coreógrafo destaca, neste período, o Centro Cultural São Paulo como um lugar de acolhimento desses artistas e suas produções. Ali os profissionais da dança não só dispunham de espaço físico para suas investigações, ensaios e treinamentos, como também de duas salas de espetáculos para apresentar suas produções. Mesmo sem aparato financeiro, a possibilidade de tornar públicas suas obras era não só um 
desejo natural, como também uma forma de validar e reconhecer esses artistas que não tinham, por opção, o respaldo de pertencer a um corpo estável, e também não contavam com políticas culturais voltadas para este segmento.

Antes de fazer parte da dança independente paulistana, Sandro Borelli compôs o elenco do Balé Teatro Guaíra, do Ballet Ópera Paulista e do Balé da Cidade de São Paulo. Começou as suas experimentações quando ainda bailarino desta última Companhia e passou a dedicar-se exclusivamente à cena independente a partir do ano de 1992.

Sua trajetória artística é marcada pela escolha de temas densos: explora os conflitos da existência humana e aborda a morte com recorrência. O poeta Augusto dos Anjos e o escritor Franz Kafka foram pesquisas importantes em seu percurso artístico, revelando o homem solitário, o corpo que se autoflagela, a impossibilidade de salvação. Pela forma como constrói os movimentos e a cena, pela baixa intensidade da luz e pelo clima que instaura, nos primeiros minutos de espetáculo, o espectador que acompanha a obra já identifica o seu autor, pois Sandro Borelli é reconhecido por uma escritura diferenciada e autoral.

Em 1997 ele cria a FAR-15, hoje Cia Borelli de Dança, passando a ter o seu próprio núcleo artístico no qual é coreógrafo e diretor, tendo sido também intérprete até o ano de 2005. Dos 15 anos de existência da Cia Borelli, 10 são anteriores ao primeiro edital de Fomento à Dança e, durante esse período, o trabalho de Sandro Borelli foi contemplado por alguns editais, prêmios e bolsas, sendo, duas vezes pela Bolsa Vitae (1996 e 2001), uma vez pelo Prêmio em Cena Brasil (2002), uma vez pelo Braços e Pernas pela Cidade (2003), uma vez pela Cultura Inglesa Festival (2004), uma vez pela Caixa Cultural (2005) e uma vez pelo Klauss Vianna (2006). Ressalta-se que, à exceção da primeira Bolsa Vitae, todos esses subsídios situam-se nos anos 2000, não tinham como foco a manutenção de grupos artísticos e sim ações específicas, e totalizavam uma verba que, atualizada, corresponderia em média a 20 por cento da verba destinada pelo Programa de Fomento à Dança a cada projeto.

Diante desse cenário, constata-se que foram necessários 10 anos de existência para que a Companhia adquirisse alguma estabilidade financeira, passando a manter o seu elenco com um cachê mensal vindo de verba prioritária, porém não exclusiva, do Fomento à Dança. Pois alguns outros editais, como o Programa de Ação Cultural do Estado de São Paulo (PROAC), além de outras subvenções vindas do circuito SESI e do circuito Cultural Paulista, contribuíram para esta "estabilidade dependente". 
Essa questão de trabalhar com remuneração é sem dúvida, segundo Sandro Borelli (2012), a maior diferença na sua estrutura de trabalho, antes e depois dos editais. No entanto, o artista ressalta que desde sempre, com ou sem verba, o trabalho é diário e ininterrupto, ou seja, não se trabalha apenas para executar um projeto ou cumprir uma temporada, os encontros diários foram e são rigorosamente mantidos independentes da agenda da Companhia.

Como consequência da possibilidade de remuneração e ampliação do mercado profissionalizante da dança, perguntado sobre as possíveis diferenças criativas e dramatúrgicas em sua obra, o coreógrafo aponta para a questão que mantém as pessoas juntas. $O$ estar junto antes era prioritariamente uma identificação artística e hoje é a existência de uma relação de trabalho:

Eu sou de uma época, anos 90, que era muito luxo você conseguir trabalhar com um cenógrafo, um iluminador... Geralmente, quando se trabalhava com essas pessoas, era por uma relação de amizade. O que se perdeu, que não é uma crítica, mas uma constatação, é que hoje em dia já está implícito que você vai pagar aquelas pessoas e, nos anos 90, a primeira coisa que vinha à cabeça é: eu vou participar desse trabalho artístico. (BORELLI, 2012)

O fato da dança paulistana nos anos recentes passar a gerar empregos desencadeou mudanças estruturais nos processos internos dos artistas e seus núcleos. No caso da Cia Borelli, o compromisso dos profissionais envolvidos era, e continua sendo, um compromisso com a proposta artística. Mas isso se diluiu nos últimos anos e, como consequência, a dramaturgia dos trabalhos foi afetada.

Segundo definição dada por Jean-Marc Adolphe 5 "dramaturgia não é a resolução de um elemento dentro do outro (o sentido dentro da ação ou o inverso), mas a dialética que se estabelece entre ação e sentido" (1997, n.p.). Se pensarmos que a dramaturgia em dança está na construção de sentidos, e que esses sentidos se materializam nas ações, e que essas ações se dão nos corpos dos artistas intérpretes, não há como não relacionar o modo como esses artistas entendem a proposta criativa com o modo como se colocam na cena. Não há que se falar em intérprete que executa um movimento sem nenhum discernimento de suas ações. Há que se falar sim, em formas de apropriação da ação e que fazem toda a diferença na dramaturgia do movimento. Nesse sentido, também não há que se falar em produto artístico desconsiderando o percurso da criação, pois se entende que "a obra não é fruto de uma grande ideia localizada em momentos iniciais do processo, mas está espalhada pelo percurso"

\footnotetext{
${ }^{5}$ Jornalista, redator-chefe da revista francesa "Mouvement", especializou-se em crítica de dança e teatro e foi
} conselheiro artístico do Teatro da Bastilha de Paris de 1994 a 2002. 
(SALLES, 2006, p.36). Ou seja, tem-se como princípio que o produto artístico e o artista não estão descolados do processo criativo, tão pouco isolados ou alheios à realidade sócio-política em que se inserem.

Daí a necessidade de se pensar a criação artística no contexto da
complexidade, romper o isolamento dos objetos ou sistemas, impedindo
sua descontextualização e ativar as relações que os mantêm como sistemas
complexos. Uma decisão do artista tomada em determinado momento tem
relação com outras anteriores e posteriores. Do mesmo modo, a obra vai se
desenvolvendo por meio de uma série de associações ou estabelecimento de
relações. A 'anotação no guardanapo do bar', muitas vezes, não é nada mais
que a tentativa de não deixar uma associação se perder (SALLES, 2006, p.27).

Pensar, tal qual propõe Salles, que a criação situa-se no "campo das relações" implica considerar as questões internas da obra e de seu criador em consonância com tudo o que os cercam. O ato criador, portanto, afeta e é afetado pelo que está "dentro e fora", pelas questões intrínsecas e extrínsecas à criação, uma contaminando a outra.

Sandro Borelli reconhece que sua criação artística é um processo solitário, e grande parte do seu trabalho é centralizado nele próprio. Suas produções possuem uma simplicidade que lhes é característica: caixa preta, sem cenário e sem grandes adereços; figurinos escuros, e propositadamente sem destaque algum; luz sem muitos efeitos e em baixa intensidade. Sua escritura coreográfica é permeada de detalhes, é focada no movimento, no estudo minucioso dos gestos. Para o coreógrafo (2012), "criar é um trabalho artesanal.' Uma massa de modelar ilustraria o que ele faz muitas vezes no seu processo coreográfico, verbaliza, ou mostra nos corpos dos bailarinos a forma imaginada, fazendo o desenho de cada uma delas com suas próprias mãos. As formas unidas, uma após a outra, tornam-se movimento. Toda a estrutura coreográfica parte dele. Não há trabalho de improvisação, jogos, ou propostas construídas pelo elenco. Há, sim, um trabalho de estudo coletivo, investigação, apropriação e refinamento do que ele criou. Talvez esse método totalmente centralizado no coreógrafo não seja mais tão usual nos trabalhos de pesquisa atuais de grupos independentes. De fato o bailarino vem ganhando um espaço nas criações no campo da autoria, sendo cada vez mais comum esse crédito ser compartilhado nas fichas técnicas de espetáculos de dança.

Na Cia Borelli de Dança isso tem sido quase que um percurso inverso. Antigamente o elenco, embora também não tivesse participação direta na elaboração do material coreográfico, apropriava-se dele de uma forma mais autoral, personalizada. Sandro Borelli (2012) percebe claramente esta mudança: "Eu não encontro eco na minha fala... Eu tenho eco, mas é um eco muito menor. Eu fui ficando cada vez mais 
solitário". Mas isso para ele não é um problema, pelo contrário, acredita que aprimorou a sua maneira de criar, tornou-se menos passional, passando a ter um distanciamento necessário de suas obras, o que proporcionou um refinamento.

O fato de trabalhar com artistas da "geração dos editais", mais jovens e habituados a produzir na condição de trabalhadores remunerados, tornou questionável o tipo de parceria que se formava nos processos de criação. Essa nova configuração, ao mesmo tempo em que afastou Sandro Borelli do elenco, tornou o seu trabalho mais independente: "Eu fui sofisticando a minha maneira de trabalhar, porque fui me adaptando também. Eu acho que fui aprendendo a fechar a dramaturgia de um jeito que, estando o intérprete ali ou não, não iria afetar a coisa" (BORELLI, 2012). Quando se refere ao intérprete estar ali ou não, refere-se a um intérprete específico, porque o coreógrafo tem sim, no corpo do artista, o lugar em que se funda a sua dramaturgia. Seu gestual é extremamente sutil, é preciso estar atento aos menores detalhes de um dedo que aponta, das mãos que se esfregam, das pequenas mudanças de direção do olhar que se mantém quase que sempre numa diagonal baixa. Esses detalhes caracterizam seu trabalho, que não se utiliza de virtuosismo e busca na simplicidade e na síntese a sua dramaturgia cênica.

O Fomento à Dança também proporcionou a remontagem de trabalhos antigos e a possibilidade de se manter um repertório ativo. Até o ano de 2004 a Cia Borelli dedicava longos períodos à uma única obra. Não costumava ensaiar e nem se apresentar com duas criações no mesmo período. Foram, por exemplo, 3 anos de investigação para criar "Senhor dos Anjos" (2001). Isso se modificou consideravelmente nos últimos tempos chegando a realizar, num mesmo projeto, 4 remontagens, o que significava ensaiar obras diferentes simultaneamente, numa rotina completamente diferenciada do que lhe era comum quando não existiam subvenções.

Quando restrito a uma mesma obra, o processo de investigação da Companhia era mais específico, mais duradouro e mais intenso, e sua preparação corporal era desenvolvida exclusivamente pelo seu coreógrafo. Atualmente, com a disponibilidade de verba, configura-se outra forma de preparação corporal, professores são contratados, tanto de técnica clássica quanto contemporânea, independente do trabalho que está sendo ensaiado.

O elenco da Cia Borelli dos últimos anos é mais homogêneo no que se refere a tipos físicos e à experiência técnica e artística. Quando se trata de remontagens, as diferenças na estrutura interna da Companhia, no perfil dos intérpretes e na apropriação da proposta criativa são percebidas no produto artístico. O processo de remontagem 
ocorre, inicialmente, por meio da observação dos registros em vídeo e, apenas num segundo momento, por meio da interferência do coreógrafo. Sandro Borelli procura ser fiel o máximo que pode ao trabalho original e, mesmo que internamente esteja incomodado com algumas construções de movimento que parecem datadas, ele não costuma fazer grandes alterações. Entende-se que a insatisfação e o inacabamento são inevitáveis e instigam a criação. Conforme aponta Cecilia Salles, "o artista lida com sua obra em estado de contínuo inacabamento, o que é experenciado como insatisfação," e ainda "o inevitável inacabamento é impulsionador" (SALLES, 2006, p.21). A insatisfação para Borelli negocia com o desejo de preservar o momento original do ato criador, e é na condição de mudança de elenco que o coreógrafo revisita seus trabalhos e se abre para possíveis mudanças, todas muito sutis, não alterando sensivelmente a proposta inicial.

Assim como o artista não está isolado, as obras também, ao nascerem e ganharem vida própria, inserem-se no campo das relações. Um novo intérprete, num novo contexto, ressignifica a obra e sua dramaturgia. Pois se entende dramaturgia como algo móvel, que caminha junto ao processo de criação e está em constante transformação. Essa possibilidade de revisitação de obras é mais uma dentre as mudanças nos modos de produção desencadeadas pela política dos editais. Há que se ressaltar que todas as diferenças apontadas no processo da Cia Borelli após os editais são mais facilmente percebidas quando se observam as remontagens, pois elas partem de uma referência preexistente.

Também se deve mencionar neste estudo que junto aos editais deflagra-se um cenário aberto a discussões políticas, ao fortalecimento e amadurecimento da categoria da dança. Com isso, as criações de Sandro Borelli nos anos 2000 têm sofrido grande influência do seu engajamento político nas questões da dança, o que pode ser evidenciado em sua atuação como presidente da Cooperativa Paulista de Dança há quase dois anos e na criação da revista Murro em Ponta de Faca. Conforme confirma a crítica Helena Katz:

\footnotetext{
A revista foi financiada com parte da verba recebida do Fomento à dança, e complementada por recursos do próprio grupo. De partida já se configura como uma ação política, pois, em vez de usar seus financiamentos somente para seus projetos artísticos, destina parte dele para uma iniciativa da maior relevância (KATZ, 2011).
}

A carreira artística de Sandro Borelli sempre esteve próxima de discussões que questionam padrões sociais, como acontece no espetáculo "BENT - O canto preso" (1988), baseado no texto teatral de Martin Sherman que trata da relação amorosa entre dois homossexuais nos campos de concentração nazista. Essa proximidade também é 
visível em "Carne Santa" (2007), que se inspira no discurso poético de Renato Russo, e se propõe a discutir a década de 80 , em seu contexto político, social e estético. Há que ressaltar ainda o autor que reincide em sua carreira, o escritor Franz Kafka, inspiração para 7 criações da Companhia: "A Metamorfose" (2002), "O Abutre" (2003), "O Processo" (2003), "Carta ao Pai” (2004), "Kafka in off” (2007), "Artista da Fome” (2008) e "Colônia Penal" (com estreia prevista para 2013).

Sobre "O Processo", realizado pela Cia Borelli, afirmou o jornalista Mauro Fernandes: "Uma metáfora para a opressão social, para a religião punitiva, para o Estado que violenta liberdades, para a burocracia, sistema pelo qual a mediocridade exerce um poder qualquer com estreiteza de princípios" (FERNANDES, 2008, p.16). A temática kafkiana de Borelli traz à cena:

O isolamento da sociedade como consequência da inadequação à ausência de princípios de justiça e a impotência do indivíduo em fazer frente a essa aflitiva condição; a perda de identidade num planeta em que cada um não passa de impessoal peça de engrenagem; a culpa atirada às costas de quem se vê atingido pela tirania institucionalizada, o que provoca mais solidão. (FERNANDES, Mauro, 2008, p.14)

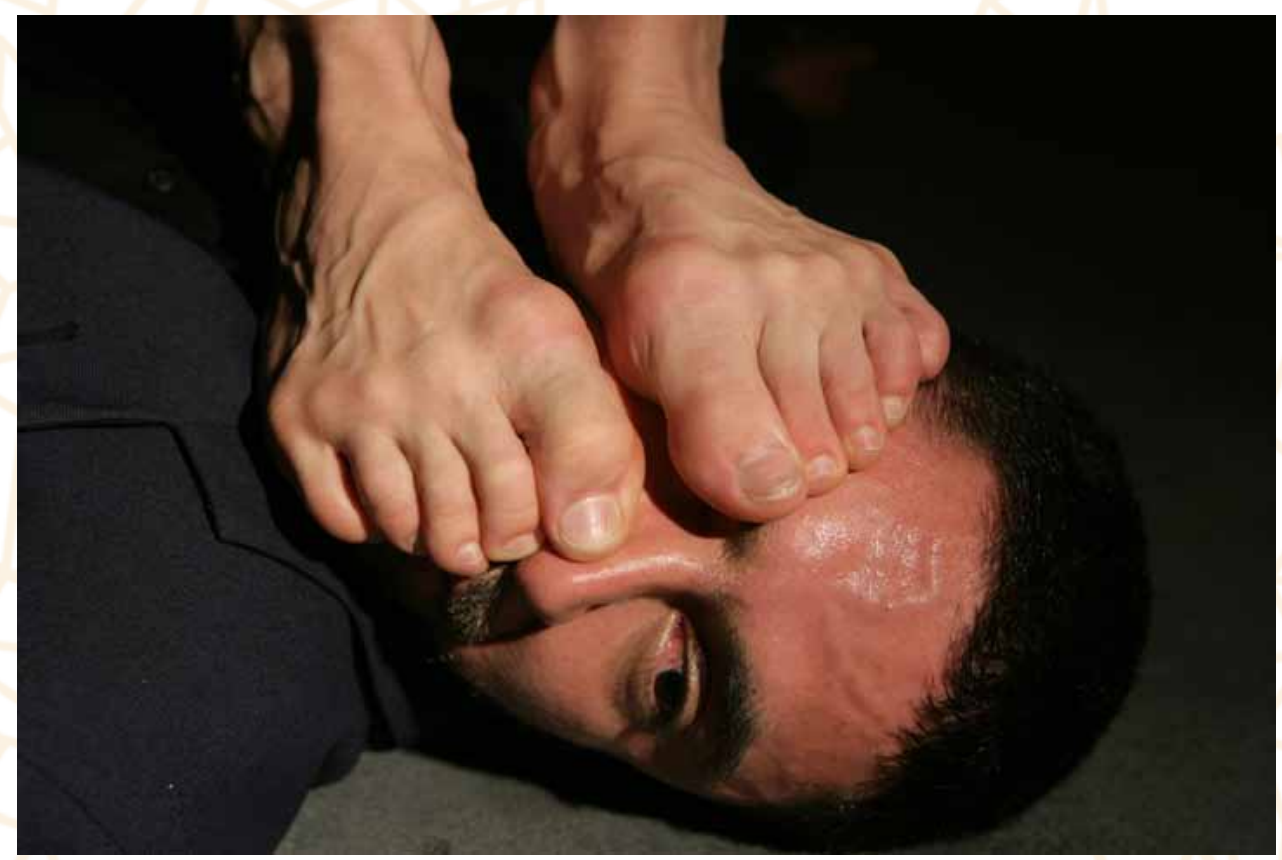

Cia Borelli de dança -"O PROCESSO” (2007) - Foto: Gal Oppido

É, no entanto, no ano de 2009, que o artista resolve, de forma mais explícita, nas suas próprias palavras, "caminhar em direção a uma arte mais engajada", quando cria "Estado Independente", inspirado em Che Guevara. Nesta criação, durante os seus 50 minutos de duração, um lampião é passado de um bailarino para o outro, enquanto dançam em grupo. Em referência ao objeto cênico, escreveu a crítica Helena Katz: 
“Quando um passa para o outro o 'lampião', agrega a essa questão estética um viés político: escancara o sentido de que isso acontece quando se age em colaboração" (KATZ, 2009). Também nos diz na mesma matéria: "A inventividade nos pas de deux é pontuada por um uso do grupo como 'corpo de baile', e esta escolha promove uma boa discussão sobre as diferenças do que hoje significa ser massa/povo/multidão".

As criações da Cia Borelli hoje propõem um olhar para o "grupo", tanto no sentido dos artistas estarem coreograficamente dependentes um do outro, como acontece em seu penúltimo trabalho, "Produto Perecível Laico" (2011), em que uma intérprete é manipulada como boneco, do início ao fim, por outros 5 intérpretes e, para que isso aconteça, em muitos momentos, é necessário que o peso do corpo manipulado seja divido entre todos eles. Ou ainda, quando a estrutura coreográfica propõe que o grupo seja coeso, executando um mesmo movimento, como acontece em "Estado independente" ou no "Artista da fome." Mesmo quando o coreógrafo parece dar destaque para um intérprete, por ele se descolar do grupo e estar cenicamente em outra situação, como acontece em evidência em 3 trabalhos: "O Processo," "Artista da Fome" e "Produto perecível laico", para ele, o destaque está no significado da imagem, sempre indicando que qualquer um entre os demais pode "ser o próximo". Com isso, esses intérpretes, aparentemente em evidência, ali estão simbolizando, ora a morte, ora a culpa, ora o homem aprisionado pelo sistema.

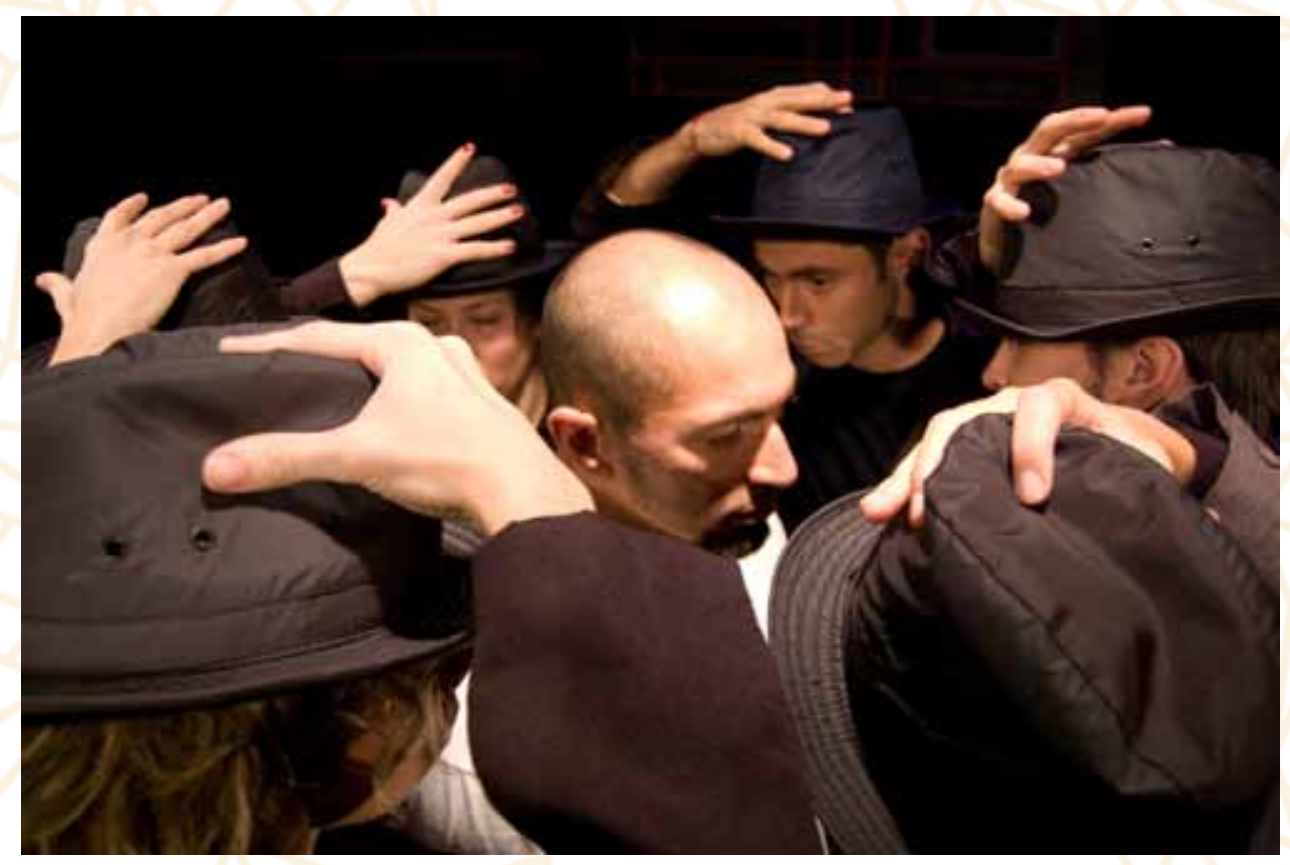

Cia Borelli de Dança, "Artista da Fome" (2008) - Foto: André Prado

O criador sente que seus trabalhos estão mais "pasteurizados", fruto talvez de um processo de criação envolvendo um elenco que se apropria menos dos questionamentos 
propostos. No entanto, sente que "pasteurizado" não é um aspecto negativo, é uma condição que revela o momento atual da dança na cidade de São Paulo, e o seu próprio amadurecimento como artista. As obras da Cia Borelli, de um lado, dependem absolutamente de um elenco comprometido e bem preparado tecnicamente e artisticamente, pois se valem quase que inteiramente da estrutura coreográfica, da proposta de movimento. De outro lado, cada vez mais, independem da individualidade de quem compõe o elenco, pois algo maior está consolidado como escritura coreográfica - as questões ali expostas. E, mesmo que obviamente qualquer questão tenha uma relação estreita com quem a coloca, o processo criativo da Cia Borelli não se pauta nas habilidades individuais, nem na forma pessoal de realizar uma ação, e nem numa particularização de sentido para as questões que discute. Como consequência, sua escritura artística se revela na busca de uma autonomia, num desejo de que a obra, mesmo sendo de dança e lidando com o efêmero, tenha uma vida independente tanto dos intérpretes, quanto do próprio coreógrafo.

\section{Referências bibliográficas}

ADOLPHE, J. M; KERHOVE, M. V; PICKELS, Antoine. Dossier Danse et Dramaturgie, in Nouvelles de Danse. Contredanse, 31. Bruxelles, 1997.

FERNANDO, Mauro. Cia Borelli de Dança - Sonhos Intranquilos. São Paulo: edição do autor, 2009.

PAIS, Ana; SAADI, Fátima; SOTER, Silvia; ROCHA, Tereza. Temas para a Dança Brasileira. Organização Sigrid Nora. São Paulo: Edição Sesc SP, 2010.

SALLES, Cecília Almeida. Gesto Inacabado Processo de Criação Artística. São Paulo: Annablume, 1998.

Redes da Criação. Construção da Obra de Arte. São Paulo: Horizonte, 2006.

SÃO PAULO, Secretaria Municipal de Cultura. . Fomento à Dança 5 anos. São Paulo: Secretaria Municipal de Cultura, 2012.

\section{Referências eletrônicas}

BORELLI, Cia de Dança. Disponível em: <http://www.ciaborellidedanca.blogspot.com.br/p/ repertorio.html>. Acesso em: 28 de set. de 2012.

PROGRAMA, Municipal de Fomento à Dança. São Paulo, 2012. Disponível em: <http://www. prefeitura.sp.gov.br/cidade/secretarias/cultura/fomentos/danca/>. Acesso em: 27 de set. de 2012.

KATZ, Helena. Estado independente aponta um novo caminho da composição. O Estado de S. Paulo, 02 de set. de 2009. Disponível em <http://www.helenakatz.pro.br/midia/ helenakatz21252074902.jpg >. Acesso em: 20 de set. de 2012

. Resistência e Inspiração. O Estado de S. Paulo, 27 dez. 2011. Disponível em < http:// www.helenakatz.pro.br/midia/helenakatz81325848774.jpg >. Acesso em 20 de set. de 2012. 